\title{
Arquitetura foliar de Odontonema strictum (Nees) O. Kuntze (Acanthaceae) em duas condições de luminosidade
}

\author{
Letícia Larcher ${ }^{1}$ e Maria Regina Torres Boeger ${ }^{2,3}$
}

Recebido: 23.10.2008; aceito: 14.05.2009

\begin{abstract}
Leaf architecture of Odontonema strictum (Nees) O. Kuntze (Acanthaceae) in two light conditions). This study investigated the morphological characteristics that influence the foliar architecture of Odontonema strictum, under two light conditions. Branches of 15 individuals from high and low light were collected at the "Centro Politécnico" of the Universidade Federal do Paraná, Curitiba, PR. Leaf angle, leaf area, dried mass, lamina thickness, foliar density, length, diameter, dried mass and volume of the petiole were analyzed. Mean length of the internodes and petioles were greater in low light condition while the remaining traits showed statistically greater mean values in high light condition. The morphological variations observed for $O$. strictum did not agree with the data described in other studies, under the same conditions. The morphological adjustments and their combined action seem to be determinant of the best leaf architecture pattern on a given light condition, allowing the species expand the exploitation of niches with more resources, especially those with heterogeneous environments related to light conditions.
\end{abstract}

Key words: leaf morphology, shade leaves, sun leaves

RESUMO - (Arquitetura foliar de Odontonema strictum (Nees) O. Kuntze (Acanthaceae) em duas condições de luminosidade). Os atributos morfológicos que influenciam a arquitetura foliar de Odontenema strictum foram investigados em duas condições de luminosidade. Ramos de 15 indivíduos de sol e sombra foram coletados no Centro Politécnico da Universidade Federal do Paraná, Curitiba, PR. O ângulo, área, massa seca, espessura e densidade das folhas, comprimento, diâmetro, massa seca e volume do pecíolo foram mensurados. Os comprimentos do internó e do pecíolo foram significantemente maiores em folhas de sombra, enquanto que as demais variáveis foram maiores nas folhas de sol. As variações morfológicas de $O$. strictum não corresponderam àquelas encontradas em outros estudos, sob as mesmas condições. Os ajustes morfológicos e a ação combinada dos mesmos parecem ser determinantes na definição do melhor padrão de arquitetura da folha numa dada condição de luz, permitindo assim que a espécie amplie a exploração em nichos mais ricos em recursos, principalmente nos ambientes mais heterogêneos quanto à condição de luz.

Palavras-chave: folhas de sol, folhas de sombra, morfologia foliar

\section{Introdução}

A organização tri-dimensional das folhas no eixo caulinar, definida como arquitetura foliar (Reinhardt $\&$ Kuhlemeier 2002), é considerada um fator limitante na distribuição da radiação solar (Valladares \& Brites 2004). A arquitetura foliar resulta da combinação de vários atributos morfológicos, tais como o ângulo foliar (que corresponde ao ângulo formado entre o pecíolo e o ramo), segundo Falster \& Westoby (2003), a área, a massa, a espessura da lâmina foliar (Gálvez \& Pearcy 2003), filotaxia (Niklas 1999) e o comprimento e o diâmetro do pecíolo (Takenaka et al.2001, Johnson et al.2005). Segundo Valladares \& Brites (2004), a eficiência na captura de luz pelas folhas é o resultado final da combinação desse conjunto de características. Variações destes atributos expressos na morfologia foliar são respostas às diferentes condições ambientais onde as plantas se desenvolvem (Percy et al. 2005) e, tais variações, podem ocorrer tanto entre indivíduos da mesma espécie como entre as folhas do mesmo indivíduo (Gutschick 1999).

Dentre os vários aspectos da arquitetura foliar, a orientação das folhas (ângulo foliar) é um dos determinantes no processo de captura de luz e balanço energético da folha (Gálvez \& Pearcy 2003). A variação do ângulo foliar entre indivíduos da mesma espécie influencia diretamente na estrutura interna da

1. Programa de Pós-Graduação em Ecologia e Conservação, Setor de Ciências Biológicas, Universidade Federal do Paraná

2. Universidade Federal do Paraná, Setor de Ciências Biológicas, Departamento de Botânica, Laboratório de Morfologia e Ecologia Funcional de Plantas, Caixa Postal 19031, 81.531-990 Curitiba, PR, Brasil

3. Autor para correspondência: rboeger@ufpr.br 
folha (Falster \& Westoby 2003). Assim, é esperado que folhas menores, mais espessas e com menores ângulos foliares, em relação ao eixo da planta, ocorram em ambientes com mais intensidade luminosa, enquanto que folhas maiores, menos espessas e com maiores ângulos ocorram em locais de menor intensidade luminosa.

A filotaxia, que consiste no arranjo das folhas ao redor do eixo caulinar, também está associada às demais características foliares na otimização na captura de luz (Valladares \& Brites 2004). Para alguns autores, a extensão em que a filotaxia influencia na captura de luz ainda é pouco entendida devido à grande interação de vários parâmetros foliares para compensar a baixa eficiência de alguns tipos de filotaxia (Niklas 1999). Segundo Valladares \& Brites (2004), a filotaxia espiralada é mais eficiente na captura de luz, devido à menor sobreposição de folhas. Por outro lado, a filotaxia decussada (oposta cruzada) possui cerca de $45 \%$ de eficiência na captura de luz, o que representa maiores custos energéticos em termos de ganho de carbono (Gálvez \& Pearcy 2003).

Odontonema strictum (Nees.) O. Kuntze (Acanthaceae) caracteriza-se pelo hábito arbustivo, de porte ereto, com 1 a 2 metros de altura, com folhas simples, decíduas, ovaladas-alongadas, verde brilhante, espessas, textura áspera, bordos ondulados e venação pinada. Tolera solos ácidos, alcalinos e argilosos (Lorenzi \& Moreira 1995, DelValle \& Gilman 1999). A espécie é muito utilizada como ornamental, multiplicando-se facilmente por estacas (Zuffellato-Ribas et al. 2005).

Considerando que esta espécie apresenta filotaxia oposta cruzada (ou decussada) e que este tipo de filotaxia induz condições diferenciadas de luz para as folhas de um mesmo indivíduo, este estudo teve como objetivo comparar a arquitetura foliar de $O$. strictum em duas condições distintas de luminosidade, identificando as variações morfológicas da arquitetura foliar e as implicações destas variações sobre o processo de captura de luz.

\section{Material e métodos}

Indivíduos de $O$. strictum foram coletados no Jardim Didático do Centro Politécnico da Universidade Federal do Paraná $\left(25^{\circ} 25^{\prime}\right.$ 'S e $\left.49^{\circ} 17^{\prime} \mathrm{W}\right)$, localizado na região leste do município de Curitiba, no Estado do Paraná, numa altitude de aproximadamente $900 \mathrm{~m}$, em março de 2005. Segundo os dados fornecidos pelo SIMEPAR (Instituto Tecnológico SIMEPAR-
PR) para o ano de 2005, a temperatura média anual de Curitiba foi de $17,8^{\circ} \mathrm{C}$, sendo a maior temperatura média durante o mês de março com $20,7^{\circ} \mathrm{C}$ e a menor durante o mês de julho, com $13,9^{\circ} \mathrm{C}$. A precipitação anual total foi de $1.332,7 \mathrm{~mm}$, sendo outubro o mês de maior precipitação média, com 168,1 mm e dezembro o de menor precipitação, com $54,0 \mathrm{~mm}$. A intensidade luminosa de cada condição foi estimada utilizando um "light meter" Li-250A (LICOR, USA), com medições diárias, por três dias consecutivos, ao meio-dia, durante o período de coleta, apresentando uma média de 1.505,25 $\mu \mathrm{mol} \mathrm{s}{ }^{-1} \mathrm{~m}^{-2}$ para a condição de alta luminosidade (100\%) e 78,08 $\mu \mathrm{mol} \mathrm{s}{ }^{-1} \mathrm{~m}^{-2}$ para a condição de baixa luminosidade (5\%). O material testemunho foi depositado no Herbário UPCB da Universidade Federal do Paraná, sob o número 60300. Ramos de 15 indivíduos que ocorrem em ambiente de alta luminosidade, expostos totalmente ao sol e de 15 indivíduos de ambiente de baixa luminosidade, que ocorrem em áreas sombreadas pela vegetação arbórea do Jardim Didático foram coletados com auxílio de uma tesoura de poda. Foram selecionadas quatro folhas de cada individuo, entre os $3^{\circ} \mathrm{e} 4^{\circ}$ nós no sentido ápice-base, para cada condição de luz. No local da coleta, o comprimento do internó foi mensurado com uma fita milimetrada, enquanto que o diâmetro, o comprimento do pecíolo foi mensurado com auxílio de paquímetro digital.

Os ramos foram coletados com o auxílio de uma tesoura de poda, acondicionados em baldes com água e, em seguida, transferidos para o laboratório. $\mathrm{O}$ ângulo foliar, definido como o ângulo formado entre a face adaxial do pecíolo e o caule da planta, foi mensurado com o auxílio de um transferidor, imediatamente após a coleta para evitar murchamento das folhas. O volume do pecíolo foi estimado a partir da fórmula $\mathrm{VP}=\pi(\mathrm{d} / 2)^{2} \mathrm{~h}$, sendo $\mathrm{d}=$ diâmetro do pecíolo e $\mathrm{h}=$ comprimento do pecíolo.

Dois pecíolos de cada indivíduo foram fixados em FAA 70 (etanol 70\%, formaldeído e ácido acético 18:1:1 v/v) e armazenados em álcool $70^{\circ}$ (Johansen 1940). As demais folhas foram prensadas em papel jornal e desidratadas em estufa a $50^{\circ} \mathrm{C}$, até atingirem peso constante para estimar as respectivas massas secas foliares, assim como a massa seca dos pecíolos. Das folhas secas, a área foliar foi mensurada com o auxílio do programa SIGMASCAN-PRO Versão 5.0 (SPS Inc., Chicago, IL, USA, 1995), através de imagem digitalizada em "scanner" de mesa acoplado ao computador. A partir dos dados de espessura do limbo, massa seca e área foliar, foi estimada a 
densidade foliar $\left(\mathrm{DF}, \mathrm{mg} \mathrm{mm}^{-3}\right)$, onde $\mathrm{DF}=$ massa seca $(\mathrm{mg}) /$ área foliar $\left(\mathrm{mm}^{-2}\right) \times 1 /$ espessura da folha (mm) de acordo com Witkowski \& Lamont (1991).

Para a mensuração da área dos tecidos mecânicos e dos tecidos do mesofilo, secções transversais das bases dos pecíolos e da lâmina foliar, respectivamente, foram realizadas com auxílio de lâmina de barbear. As secções foram clarificadas, coradas com azul de toluidina a $0,5 \%$, montadas entre lâmina e lamínula com glicerina e posteriormente vedadas com esmalte de unha incolor (Dop \& Gautié 1928). A área de tecidos mecânicos foi estimada por meio de desenhos esquemáticos com o auxílio de câmara clara acoplada ao microscópio óptico. Os desenhos foram digitalizados em "scanner" de mesa acoplado ao computador. A área foi calculada pelo programa SIGMASCAN-PRO versão 5.0 (SPS Inc., Chicago, IL, USA, 1995). A porcentagem de tecidos mecânicos do pecíolo (PTM) foi calculada entre a razão da área total do pecíolo e a área dos tecidos mecânicos. Os tecidos constituintes do mesofilo, assim como a espessura total do limbo, foram mensuradas em microscópio óptico com ocular micrometrada.

Para todas as variáveis foram calculadas as médias e respectivos desvios-padrão. As características foliares estudadas, em duas diferentes condições de luz, foram comparadas empregando-se o teste $\mathrm{t}$, com auxílio do software STATISTICA versão 6.0 (StatSoft, Inc., Tulsa, OK, USA 1998), com um nível de significância de 5\%.

\section{Resultados}

Todas as variáveis analisadas apresentaram valores médios que diferiram estatisticamente entre as duas condições de luz. As folhas de sol apresentaram os maiores valores médios para todas as variáveis com exceção do comprimento do internó e comprimento do pecíolo (tabela 1).

O comprimento do internó das plantas de sombra foi 2,4 vezes maiores do que o comprimento dos internós das plantas de sol, enquanto que o comprimento do pecíolo foi apenas $20 \%$ maior nas folhas de sombra do que nas folhas de sol (figura 1, tabela 1). As folhas de sol apresentaram ângulos (39\%), diâmetro (40\%) e volume do pecíolo (50\%) maiores do que as folhas de sombra. A massa seca do pecíolo das plantas de sol é $42 \%$ maior do que os pecíolos das plantas de sombra, apesar desses últimos apresentarem os maiores comprimentos. $\mathrm{O}$ incremento de tecido mecânico não corresponde à proporcionalidade observada na massa seca. A percentagem de tecido mecânico nos pecíolos é maior (7\%) nas plantas de sol. As folhas de sol são em média $27 \%$ maiores em área e $60 \%$ mais pesadas do que as folhas de sombra. As espessuras do limbo e dos tecidos do mesofilo variaram em torno de $30 \%$, entre as duas condições de luz, enquanto que a densidade foliar variou em torno de $28 \%$, ambas maiores nas folhas de sol (tabela 1).

As folhas, em secção transversal, apresentaram epiderme unisseriada, com litocistos contendo cistólitos (figura 2) e tricomas glandulares. O mesofilo é dorsiventral. O parênquima paliçádico é formado por duas a três camadas de células enquanto que o parênquima esponjoso varia de 5 a 7 camadas celulares (figura 2), tanto nas folhas de sol como nas folhas de sombra. No entanto, as folhas de sol possuem as maiores espessuras dos parênquimas paliçádico e esponjoso em relação as folhas de sombra.

Em secção transversal, o pecíolo apresentou forma triangular, sendo que, na face adaxial, ocorrem duas projeções laterais (figura 3). O pecíolo é delimitado por epiderme unisseriada, com colênquima subepidérmico contínuo, formado por cerca de oito estratos celulares (figura 4).

Dispersos entre as células mais internas do colênquima e do parênquima cortical, ocorrem litocistos com cistólitos (figura 4). O sistema vascular é formado por um feixe colateral central em forma de arco (figura 3 ) e por dois feixes menores, localizados próximos as projeções laterais (figura 4). O tecido mecânico é representado principalmente por colênquima subepidérmico (figuras 3,4 ). Os feixes vasculares não apresentaram tecidos de sustentação bem desenvolvidos associados aos mesmos (figura 4).

\section{Discussão}

Os resultados obtidos nesse estudo foram diferentes dos esperados e encontrados para a maioria das investigações sobre arquitetura foliar sob ação de diferentes intensidades luminosas. A maioria dos estudos realizados sob esse enfoque (Takenaka $e t$ al. 2001, Falster \& Westoby 2003, Gálvez \& Pearcy 2003) mostra que as folhas de sol tendem a ter menores ângulos e áreas foliares e maiores massas e espessuras da lâmina.

Os menores ângulos foliares em folhas de sol, combinados com as menores áreas foliares expostas, previnem contra uma maior exposição da lâmina, pela perda de calor com correntes convectivas, o que 

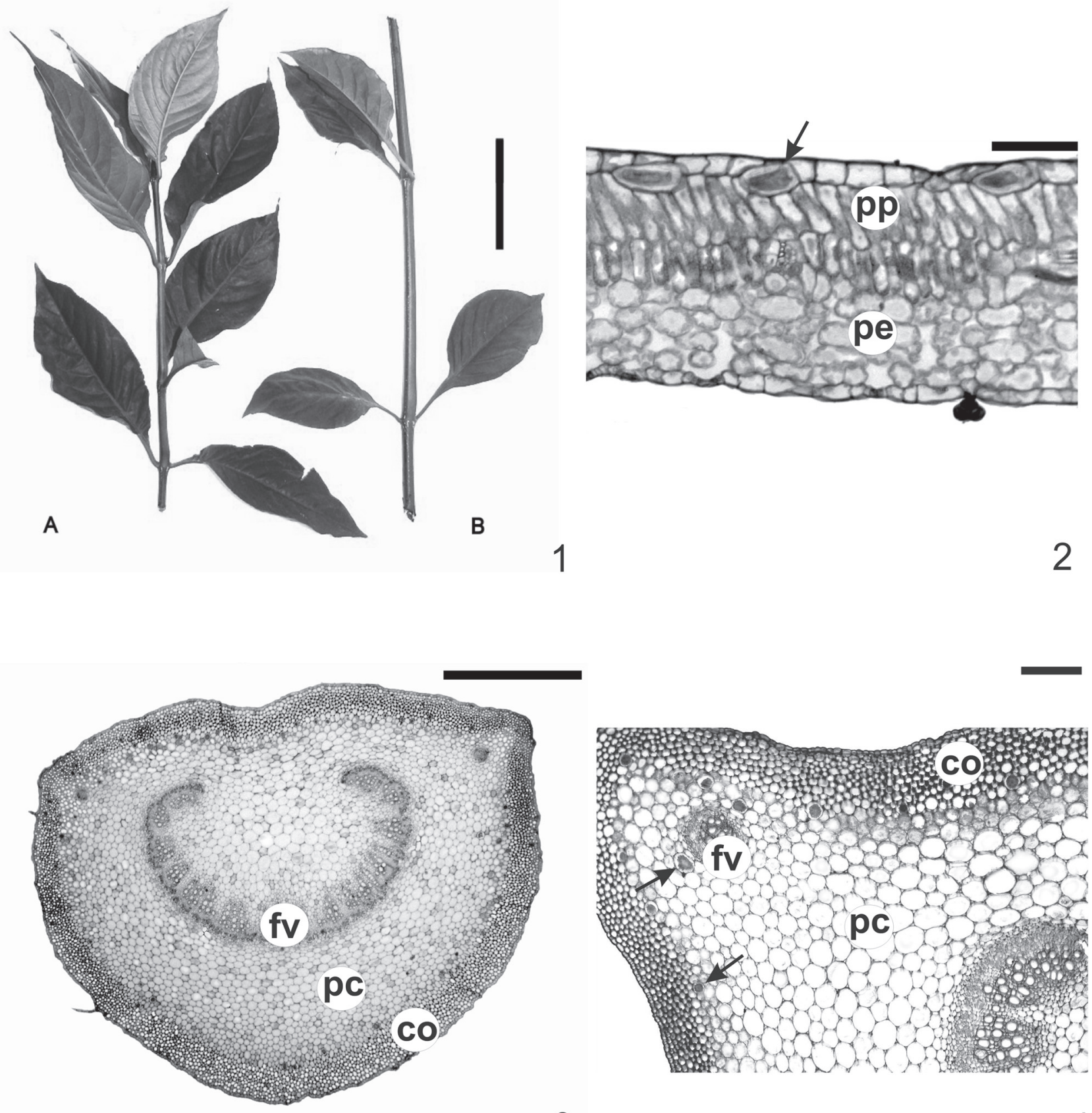

Figuras 1-4. Aspecto geral e seções transversais de folha e pecíolo de Odontonema strictum . 1. Aspecto geral dos ramos dos indivíduos: $\mathrm{A}=$ folhas de sol; $\mathrm{B}=$ folhas de sombra. 2. Secção transversal da lâmina da folha de sol, evidenciando o mesofilo. pp = Parênquima paliçádico; pe = parênquima esponjoso; seta indica cistólito. 3. Secção transversal do pecíolo da folha de sol, mostrando colênquima subepidérmico (co), parênquima cortical (pc) e feixe vascular (fv). 4. Detalhe da secção transversal do pecíolo da folha de sol, evidenciando a camada de colênquima subepidérmico (co), parênquima cortical (pc) e feixe vascular (fv); seta indica cistólito. Barras $=5 \mathrm{~cm}$ (1); $25 \mu \mathrm{m}(2) ; 1 \mathrm{~mm}(3) ; 200 \mu \mathrm{m}(4)$.

Figures 1-4. Branches and transverse sections of leaves and pecioles of Odontonema strictum 1. General aspect of branches: A = sun leaves); $\mathrm{B}=$ shade leaves. 2. Transverse section of sun leaf lamina, showing the mesophyll. $\mathrm{pp}=$ palisade parenchyma; $\mathrm{pe}=$ spongy parenchyma. Arrow indicates cystoliths. 3. Transverse section of sun leaf petiole showing subepidermical collenchyma (co), cortical parenchyma (pc) and vascular bundle (fv). 4. Detail of the transverse section of the sun leaf petiole, showing the subepidermical collenchyma (co), cortical parenchyma (pc) and vascular bundle (fv). Arrow indicates cystoliths. Bars =5 cm (1); $25 \mu \mathrm{m}(2) ; 1 \mathrm{~mm}(3) ; 200 \mu \mathrm{m}(4)$. 
Tabela 1. Valores médios e respectivos desvios-padrão, entre parênteses, das características morfológicas de Odontonema strictum em duas condições de luminosidade (sol e sombra). $\mathrm{n}=60$. Médias seguidas pela mesma letra, em linha, não são diferentes estatisticamente, ao nível de 5\% de significância. PTM = porcentagem de tecidos mecânicos.

Table 1. Mean values and respective standard deviations, between parenthesis, of morphological characteristics of Odontonema strictum in two light conditions (sun and shade). $n=60$. Means followed by same letter, in line, are not statistically different, at $5 \%$ of significance level. PTM = mechanical tissue percentage.

\begin{tabular}{|c|c|c|}
\hline & Folhas de sol & Folhas de sombra \\
\hline Ângulo do pecíolo $\left(^{\circ}\right)$ & $62,7(15,98)^{a}$ & $38,8(15,27)^{b}$ \\
\hline Comprimento do internó (cm) & $5,7(1,4)^{b}$ & $13,7(4,0)^{\mathrm{a}}$ \\
\hline Comprimento do pecíolo (mm) & $11,9(5,74)^{b}$ & $14,3(6,07)^{\mathrm{a}}$ \\
\hline Diâmetro do pecíolo (mm) & $4,9(0,47)^{\mathrm{a}}$ & $3,48(0,71)^{b}$ \\
\hline Massa seca do pecíolo (mg) & $58(18)^{a}$ & $34(18)^{b}$ \\
\hline Volume do pecíolo $\left(\mathrm{mm}^{3}\right)$ & $213,7(103,5)^{\mathrm{a}}$ & $135,7(76,10)^{b}$ \\
\hline PTM do pecíolo (\%) & $48,7(4,53)^{\mathrm{a}}$ & $45,24(4,22)^{b}$ \\
\hline Área foliar $\left(\mathrm{cm}^{2}\right)$ & $83,6(14,07)^{\mathrm{a}}$ & $65,5(26,33)^{b}$ \\
\hline Massa seca foliar (g) & $1,09(0,20)^{\mathrm{a}}$ & $0,44(0,21)^{b}$ \\
\hline Espessura do limbo ( $\mu \mathrm{m})$ & $384,15(65,99)^{a}$ & $273,97(34,22)^{b}$ \\
\hline Espessura do parênquima paliçádico $(\mu \mathrm{m})$ & $147,22(23,18)^{\mathrm{a}}$ & $95,55(25,09)^{\mathrm{b}}$ \\
\hline Espessura do parênquima esponjoso $(\mu \mathrm{m})$ & $195,97(51,27)^{\mathrm{a}}$ & $146,25(24,32)^{\mathrm{b}}$ \\
\hline Densidade foliar (mg. $\mathrm{mm}^{-3}$ ) & $0,406(0,061)^{\mathrm{a}}$ & $0,293(0,067)^{b}$ \\
\hline
\end{tabular}

reduz os níveis de radiação incidente, particularmente nas horas mais quentes do dia (Lewis 1972). No entanto, as folhas de sol de $O$. strictum tenderam a horizontalidade e a lâmina, em termos de superfície, apresentou-se bem desenvolvida (mesófilas em tamanho, de acordo com a classificação de Raunkiaer, modificada por Webb, 1959), enquanto que as folhas de sombra, apresentaram ângulos foliares menores (as folhas tenderam a verticalidade) e menor superfície. Entretanto, sob alta luminosidade, as folhas que possuem pecíolos menores e tendem a horizontalidade, podem apresentar um eventual auto-sombreamento que proporciona uma fotoproteção estrutural, minimizando os potenciais danos causados pela fotoinibição (Pearcy et al. 2005).

Aparentemente, os resultados são controversos com a literatura, mas quando se relaciona os ângulos e a área foliares com as outras características arquiteturais da planta, observam-se algumas relações que maximizam a captura de luz. O comprimento médio do pecíolo é maior nas folhas de sombra, o que projeta as folhas para maior absorção da luz. Adicionalmente, os internós são duas vezes mais longos nas plantas de sombra, permitindo uma maior distância entre duas folhas opostas consecutivas e, conseqüentemente, favorece também a maior captação de luz. Nas plantas de sol, a distância entre duas folhas opostas consecutivas é bem menor, assim como o comprimento do pecíolo, o que implica uma maior sobreposição entre as folhas e menor luz disponível o que parece justificar as maiores áreas foliares encontradas.

Considerando que as plantas encontram-se sob a mesma condição pluviométrica e edáfica, parece que a principal determinante abiótica é a intensidade luminosa. Entretanto, Smith et al. (1998) demonstraram que outros fatores, tal como a umidade local, interferem na relação entre a incidência de luz solar e a inclinação da folha. Ao estudar as associações entre a estrutura, orientação foliar e a exposição à luz solar em cinco comunidades do oeste da Austrália, estes autores verificaram que a condição hídrica tem grande influência sobre variações na morfologia e é tão importante quanto à luminosidade. Sustentam que as folhas das plantas que se desenvolvem em ambientes de alta luminosidade e baixo stress hídrico (precipitação anual maior que $100 \mathrm{~mm}$ ) possuem folhas horizontalmente orientadas e com lâminas 
grandes. Assim, pode-se dizer que a alta precipitação anual encontrada na área de estudo, parece permitir que as plantas, mesmo sob alta luminosidade, desenvolvam folhas maiores e com maiores ângulos foliares (mais horizontais).

As maiores massas secas, maiores espessuras e maior densidade parecem resultar do maior incremento da área das folhas de sol, uma vez que, com exceção da massa, as demais características das folhas de sol apresentaram um incremento em torno de $24 \%$ a $28 \%$ em relação às folhas de sombra. Estudos anteriores sobre anatomia foliar dessa espécie (Larcher \& Boeger 2006) mostraram que a lâmina é composta basicamente de tecido fotossintético, com tecido mecânico restrito ao feixe vascular e colênquima subepidérmico da nervura central. Assim, o incremento de espessura e densidade é resultante principalmente do incremento dos tecidos fotossintéticos. Em condições de luz intensa, pode ocorrer um aumento significativo na espessura do parênquima paliçádico (Rôças et al. 1997, Klich 2000), o que resulta numa maior densidade, uma vez que esse atributo é dependente da espessura (Witkowski \& Lamont 1991).

O padrão de filotaxia decussado é considerado pouco eficiente (cerca de $45 \%$ de eficiência, Valladares et al. 2002) no processo de captura de luz devido ao auto-sombreamento significativo pela posição das folhas no ramo. Entretanto, essa eficiência pode ser incrementada com a ação combinada do tamanho dos pecíolos e/ou internós. Brites \& Valladares (2005), estudando 15 espécies arbóreas do Mediterrâneo com diferentes filotaxias, observaram que a eficiência na captura de luz, combinada com o comprimento do internó, era maior nas plantas com filotaxia espiral, especialmente aquelas que apresentaram folhas com maiores áreas. Aparentemente, os ajustes entre os ângulos e os comprimentos dos internós e pecíolos geraram um efeito sinérgico na arquitetura da folha de $O$. strictum para melhorar a eficiência na captura da luz.

Uma das funções do pecíolo é a sustentação e a orientação da folha, portanto, sua organização anatômica e a disposição dos tecidos se relacionam intimamente com a área e massa foliar (Pearcy \& Yang 1998). Assim, a relação positiva entre comprimento, diâmetro e massa do pecíolo é a mais comum, pois o aumento de biomassa do pecíolo ocasiona o aumento no comprimento, sendo estes necessários e proporcionais a sustentação da massa foliar (Leeflang et al. 1998).
As folhas de sol apresentaram maiores valores médios de densidade foliar do que as folhas de sombra, o que poderia ser compensado com o aumento no volume do pecíolo e na porcentagem de tecidos mecânicos em busca de maior sustentação da folha. A relação densidade foliar/volume do pecíolo das folhas de sombra $(0,0031)$ foi maior e estatisticamente diferente que a relação das folhas de sol $(0,0022)$, indicando que nas folhas de sombra houve um maior investimento de massa, área e espessura da lâmina por unidade de volume do pecíolo. As folhas de $O$. strictum apresentaram uma relação inversa e não esperada entre diâmetro e comprimento de pecíolo, porém uma relação positiva entre o diâmetro e volume do pecíolo, resultado da maior variação do diâmetro (40\%) do que do comprimento (20\%) do pecíolo. Nas folhas de sol, houve um maior investimento no diâmetro do pecíolo para suportar uma maior superfície da lâmina (Leeflang et al. 1998), enquanto que nas folhas de sombra, o investimento maior ocorreu no comprimento do pecíolo para minimizar o auto-sombreamento (Brites \& Valladares 2005).

Esses dados corroboram com a hipótese do efeito sinérgico dos diferentes atributos da arquitetura foliar. Estudos sobre a arquitetura foliar de Miconia sellowiana, em diferentes formações vegetais, mostraram que as dimensões das folhas e do pecíolo não foram proporcionais entre as folhas das diferentes formações, contribuindo para a pouca variação dos ângulos foliares observada (Boeger, dados não publicados).

Ao contrário do esperado, não houve um investimento significativo no tecido mecânico do pecíolo, nas folhas de sol. Apesar da significância estatística, os pecíolos das folhas de sol apresentam apenas $7 \%$ mais tecido mecânico que os pecíolos das folhas de sombra, enquanto que o diâmetro apresentou um incremento de 40\%. Segundo Niklas (1999), alguns aspectos estruturais como o comprimento e diâmetro do pecíolo são relacionados à diminuição da rigidez do pecíolo e, portanto, a percentagem de tecido mecânico tende a ser menor enquanto que o comprimento e o diâmetro aumentam, em condições de menor intensidade luminosa.

As variações morfológicas apresentadas por $O$. strictum não correspondem àquelas encontradas em outros estudos (Takenaka et al. 2001, Falster \& Westoby 2003, Gálvez \& Pearcy 2003), ressaltando a importância das características arquiteturais foliares nos processos de captura de luz. A habilidade da espécie em ajustar a sua morfologia sugere uma 
plasticidade alocacional ("allocational plasticity", senso Sultan 2003) que permite a manutenção da eficiência fotossintética. Essa característica parece ser determinante no sucesso da espécie em habitar uma maior variedade de ambientes diferenciados quanto à qualidade da luz (Sultan 2003) e com isso ampliar a exploração em nichos mais ricos em recursos, principalmente nos ambientes mais heterogêneos (Cardoso \& Lomônaco 2003).

\section{Literatura citada}

Brites, D. \& Valladares, F. 2005. Implications of opposite phyllotaxis for light interception efficiency of Mediterranean woody plants. Trees 19: 671-679.

Cardoso, G.L. \& Lomônaco, C. 2003. Variações fenotípicas e potencial plástico de Eugenia calycina Cambess (Myrtaceae) em uma área de transição cerradovereda. Revista Brasileira de Botânica 26: 131-140.

Delvalle, T. \& Gilman, E.F. 1999. Odontonema strictum. University of Florida. http//:hort.ifas.ufl.edu/shrubs/ ODOSTRA.PDF (acesso em 10.09.2005).

Dop, P. \& Gautié, A. 1928. Manual of Technique Botanique. J. Lamarre, Paris.

Falster, D.S. \& Westoby, M. 2003. Leaf size and angle vary widely across species: what consequences for light interception? New Phytologist 158: 509-525.

Gálvez, D. \& Pearcy, R.W. 2003. Petiole twisting in the crowns of Psychotria limonensis: implications for light interception and daily carbon gain. Oecologia 135: 22-29.

Gutschick, V.P. 1999. Research reviews: biotic and abiotic consequences of differences in leaf structure. New Phytologist 143: 3-18.

Johansen, D.A. 1940. Plant Microtechnique. McGrawHill, New York.

Johnson, D.,Smith,W.K., Vogelmann,T.C.\& Brodersen, C.R. 2005. Leaf architecture and direction of incident light influence mesophyll fluorescence profiles. American Journal of Botany 92: 1425-1431.

Klich, M.G. 2000. Leaf variations in Elaeagnus angustifolia related to environmental heterogeneity. Environmental and Experimental Botany 44: 171-183.

Larcher, L. \& Boeger, M.R.T. 2006. Anatomia foliar de Odontonema strictum (Nees) O. Kuntze (Acanthaceae). Biotemas 19: 23-31.

Leeflang, L., During, H.K. \&Weger, M.J.A. 1998. The role of petioles in light acquisition by Hydrocotyle vulgaris L. in vertical light gradient. Oecologia 117: 235-238.

Lewis, M.C. 1972. The physiological significance of variation in leaf structure. Science Progress 60: 2551.
Lorenzi, H. \& Moreira, H. 1995. Plantas Ornamentais do Brasil. Plantarum, Campinas.

Niklas, K.J. 1999. A mechanical perspective on foliage leaf form and function. New Phytologist 143: 19-31.

Pearcy, R.W., Muraoka,H. \& Valladares,F. 2005. Crown architecture in sun and shade environments: assessing function and trade-offs with a tree-dimensional simulation model. New Phytologist 166: 791-800.

Pearcy, R.W. \& Yang, W. 1998. The functional morphology of light capture and carbon gain in the Redwood forest understory plant Adenocaulon bicolor Hook. Functional Ecology 12: 543-552.

Reinhardt,D.\& Kulhemeier, C. 2002. Plant architecture. Embo Reports 3: 846-851.

Rôças, G., Barros, C.F. \& Scarano, F.R. 1997. Leaf anatomy plasticity of Alchornea

triplinervia (Euphorbiaceae) under distinct light regimes in a Brazilian montane Atlantic rain forest. Trees 11: 469-473.

Smith, W.K., Bell, T. D. \& Shepherd, K.A. 1998. Associations between leaf structure, orientation, and sunlight exposure in five Western Australian communities. American Journal of Botany 85: 56-63.

Sultan, S.E. 2003. Phenotypic plasticity in plants: a case study in ecological development. Evolution \& Development 5: 25-33.

Takenaka, A., Takahashi, K. \& Kohyama, T. 2001. Optimal leaf display and biomass partitioning for efficient light capture in an understorey palm, Licuala arbuscula. Functional Ecology 15: 660-668.

Valladares, F., Skillman, B.J. \& Pearcy, R.W. 2002. Convergence in light capture efficiencies among tropical forest understorey plants with contrasting crown architectures: a case of morphological compensation. American Journal of Botany 89: 1275-1284.

Valladares, F. \& Brites, D. 2004. Leaf phyllotaxis: Does it really affect light capture? Plant Ecology 174: 11-17.

Webb, L.J. 1959. A physiognomic classification of Australian rain forests. Journal of Ecology 47: 551570.

Witkowski, E.T.F. \& Lamont, B.B. 1991. Leaf specific mass confounds leaf density and thickness. Oecologia 88: 486-493.

Zuffellato-Ribas, C. K., Boeger, M.R.T., Bona, C., Paes, E.G.B., Pimenta, A.C. \& Masuda, E.T. 2005. Enraizamento e morfoanatomia de estacas caulinares de Odontonema stricutum (Nees) O. Kunze. Revista Brasileira de Horticultura Ornamental 11: 57-61. 